\title{
Capital Social das Comunidades Beneficiadas pelo Programa de Combate à Pobreza Rural - PCPR/Projeto São José - PSJ - Estado do Ceará
}

Ahmad Saeed Khan ${ }^{1}$ Lucia Maria Ramos Silva ${ }^{2}$

Resumo: A proposição deste estudo foi identificar e analisar o capital social tangível e intangível de comunidades beneficiadas com os recursos do Programa de Combate a Pobreza Rural -PCPR/Projeto São José no Estado do Ceará. Os dados são originários de entrevistas diretas com beneficiários e líderes de comunidades onde foram implantados subprojetos de abastecimento de água, ação fundiária, eletrificação rural e mecanização agrícola. Determinou-se o índice de capital social para cada subprojeto. Os resultados indicaram que as associações possuem um nível médio de acumulação de capital social e que os recursos aplicados pelo PCPR/PSJ contribuíram para avançar na acumulação deste capital nas associações e/ou comunidades.

Palavras-chave: Capital social, desenvolvimento, Ceará.

Classificação JEL: Z13

Abstract: The objective of this study was to identify and analyze tangible and intangible social capital of benefited communities by the resources of rural Poverty Reduction Program in the state of Ceará. The data were

\footnotetext{
${ }^{1}$ Professor doutor do Departamento de Economia Agrícola da Universidade Federal do Ceará (UFC), bolsista do CNPq. E-mail: saeed@ufc.br

${ }^{2}$ Professora Livre Docente do Departamento de Economia Agrícola. E-mail: $\underline{\text { lramos@ufc.br }}$
} 
obtained by interviewing individuals and leaders of communities benefited by projects such as water supply, land reform, rural electrification and agricultural mechanization. For each type of project, social capital index was constructed. The results indicated that communities have medium level of social capital accumulation and resources supplied by this program contributed to increase social capital in these communities.

Keywords : Social Capital, Development, Ceará

\section{JEL Classification: Z13}

\section{Introdução}

O Governo do Estado do Ceará, na tentativa de minorar os problemas e promover o desenvolvimento do setor rural, fez novos ajustes, no ano de 1995, no Programa de Apoio ao Pequeno Produtor (PAPP), denominando-o de Projeto São José (PSJ), cujo objetivo principal era a implementação de ações de desenvolvimento sustentável no Estado com participação ativa das comunidades, tendo em vista a aumentar o acesso das populações rurais mais pobres às atividades de geração de emprego e renda, assim como a provisão de serviços sociais básicos e de infra-estrutura como meios para a redução da pobreza rural. Em 1996, o Projeto São José passou a denominar-se Programa de Combate à Pobreza Rural (PCPR). Neste sentido, foram financiados e implantados, no período aproximado de 1996 a 1998, vários subprojetos relacionados a infra-estrutura, produção e desenvolvimento social em comunidades distribuídas em municípios situados em diferentes microrregiões do Estado, CEARÁ (1998).

Como se sabe, o desenvolvimento econômico requer melhoria da qualidade de vida. É necessário, no entanto, desenvolvimento social concomitante, para que o desenvolvimento econômico seja satisfatório. Neste contexto, o conceito de capital social tem ganhado espaço devido à percepção de seus impactos na reformulação das práticas de desenvolvimento. Trata-se de um novo enfoque que procura fortalecer a capacidade dos pobres para melhorar sua situação através da associação e do desenvolvimento da confiança. Este enfoque considera que o trabalho 
social das pessoas pode possibilitar a resolução de problemas comuns KLIKSBERG, (2000), BANCO MUNDIAL, (2001 a), KNACK (1997).

Neste estudo, pretende-se verificar e analisar o efeito do Programa de Combate à Pobreza Rural - PCPR/Projeto São José (PSJ) - sobre o capital social de comunidades selecionadas que foram beneficiadas com o referido programa. Para tanto, será considerado um ponto de partida, ou seja, uma situação prévia à implantação dos subprojetos para buscar discriminar seus efeitos nos períodos subseqüentes.

\section{Metodologia}

\section{Aspectos Conceituais}

Nos últimos anos o interesse dos cientistas sociais no estudo do capital social, bem como, na confiança entre os indivíduos, no associativismo e nas redes de relações sociais foi intensificado.

Estudos empíricos elaborados pelo sociólogo Robert Putnam na Itália Contemporânea, sobre os aspectos condicionantes que influenciaram no desenvolvimento regional desigual entre o Sul e o Norte mostraram que a comunidade cívica está estreitamente ligada aos níveis de desenvolvimento econômico destas regiões.

A inovação no estudo de Putnam (2000), está na inclusão da concepção de capital social e suas implicações no desenvolvimento econômico. Para o autor, capital social compreende características da organização social, confiança, normas e sistemas que contribuem para aumentar a eficiência da sociedade, facilitando as ações coordenadas. O capital social quando presente em uma sociedade, fortalece a tomada de decisões e a execução de ações colaborativas que beneficiam toda comunidade.

A nova sociologia econômica difundiu o conceito de capital social nos meios de pesquisa. Todavia, Granovetter (1985), fez severa crítica ao comportamento econômico considerando que a subsocialização vê o indivíduo de forma mecanizada, enquanto a sobre-socialização condiciona os agentes a comportarem-se como fantoches. Para superar essa divisão, o sociólogo propõe a adoção de "embeddednes" ou "enredada”, atribuindo aos indivíduos a idéia de encaixamento em uma rede "net work” de relações interpessoais. Ou seja, os indivíduos escolhem, mas 
não "às cegas, dentro de uma ordenada rede de conexões com outros agentes, suas potencialidades e possibilidades de atuação”.

Sem se reportar ao termo capital social, Granovetter acena para o potencial que essas relações têm para resolver o "dilema do prisioneiro" e promover a confiança que um terá que ter no outro - fonte de capital social que afeta os custos entre os agentes econômicos (LAZZARINI et al, 2003).

Várias são as definições para capital social. Putnam (2000, p.177) define capital social como sendo: características da organização social, como confiança, normas e sistemas que contribuem para aumentar a eficiência da sociedade, facilitando as ações coordenadas. Grootaert apud Jara (1999) define capital social como o aglutinante que junta a sociedade. Para o Banco Mundial, a quantidade, qualidade e persistência das interações sociais entre vizinhos, amigos e membros, assim como a habilidade do trabalho em conjunto procurando o bem comum, gera capital social. O capital social é especialmente importante para o pobre já que pode ser usado como substituto do capital humano e do capital físico (WORLD BANK, http: worldbank.org).

A literatura classifica capital social em: Bonding social capital, que envolve os vínculos entre agentes da mesma posição, denominado por Putnam de a "super cola sociológica"; bridging social capital, é a forma de capital social que se refere aos laços fracos entre os agentes de grupos sociais distintos. Trata-se de um "óleo lubrificante social” que quando existe em abundância leva a uma sociedade fluida e integrada, na qual a despeito das diferenças sociais, pobres e ricos compartilham de informações (Putnam³ apud Monastério, 2003a); linking social capital refere-se às ligações entre os pobres e as pessoas em postos de comando em organizações formais. Comunidades onde esse tipo de capital é abundante têm governos permeáveis às demandas oriundas dos extratos inferiores da pirâmide social (WOOLCOCK ${ }^{4}, 1999$; World Bank ${ }^{5}, 2003$ apud MONASTÈRIO, 2003 b).

Segundo o mesmo autor, a literatura que relaciona capital social e po-

\footnotetext{
${ }^{3}$ PUTNAM, R.D. Comunidade e democracia: a experiência da Itália moderna. Rio de Janeiro: Fundação Getúlio Vargas, 1997.

${ }^{4}$ WOOLCOCK. Managining risks,skocks, and opportunity in developing economies: the role or social capital.Washington, Dc: World Banck, 1999. (mimeo)

${ }^{5}$ WORLD BANK. World Bank Development Report 2000-2001. Disponível em: http:// www.worldbank.org
} 
breza, afirma que especialmente nos países subdesenvolvidos, os pobres têm acesso a fartos estoques de bonding social capital pouco bridging e quase nenhum linking. Isto significa que a união entre os menos favorecidos economicamente fornece-lhes apoio mútuo, mas por outro lado dificulta a fluidez social em sentido vertical, o que facilita a inércia de políticas governamentais direcionadas para os pobres de modo geral.

De acordo com Fox (1996) um ambiente positivo seria a primeira coluna de sustentação para estimular a acumulação do capital social. Este autor concorda com Putnam ao afirmar que o legado histórico de um povo é importante, mas discorda da afirmação de que o legado histórico é um fator determinante na criação do capital social. Outra coluna de sustentação seria a possibilidade de interação e integração entre as diversas organizações existentes, principalmente em comunidades que se encontram isoladas geograficamente. Brown e Ashman (1996) mostram que a participação de diversos setores com diversos níveis do poder (estado, comunidade, organização não governamental e bancos de desenvolvimento) na implementação de programas de desenvolvimento têm maiores chances de sucesso, criando capital social através das interações dos participantes, sendo benéfico na hora de solucionar futuros problemas.

Fukuyama (1999) considera que o Estado pode ser importante no estímulo do capital social na sociedade das seguintes maneiras: a) deve estar atento para estimular alguma forma de aumentar o estoque de capital social já existente, como o apoio a programas de micro crédito, onde o índice de inadimplência é quase zero; b) realizando investimento e estimulando a educação, pois é na escola que se formam futuros líderes e cidadãos. Esse estímulo não deve parar no ensino fundamental ou secundário, mas prosseguir até o ensino superior; c) fornecendo bens públicos de forma eficiente e de qualidade, garantindo o direito à propriedade e segurança pública eficiente; d) descentralizando de forma a permitir um fluxo mais rápido e eficiente de serviços, permitindo também uma participação da sociedade na administração pública.

\section{Método de Análise}

O capital social foi analisado considerando tanto o capital intangível como o tangível. A acumulação do capital social intangível nas comuni- 
dades selecionadas foi avaliada através do Índice de Capital Social (ICS), e resultou da agregação das seguintes variáveis: participação dos sócios nas tomadas de decisões; número de sócios; contrapartida da comunidade; operação e manutenção dos subprojetos; cota (taxa) mensal; fonte própria de recursos; fonte externa de recursos; participação da associação na negociação de empréstimos; representação em conselhos municipais; capacidade de mobilização; renovação do corpo de dirigentes das associações; promoção de eventos sociais e inclusão social. Assim, o índice de capital social para as comunidades beneficiadas foi definido como:

$$
\text { ICS }=\sum_{i=1}^{n} C_{i}
$$

A contribuição de cada variável no ICS das comunidades foi obtida da seguinte maneira:

$$
\mathrm{C}_{\mathrm{i}}=\frac{\sum_{\mathrm{j}=1}^{m} \mathrm{E}_{\mathrm{j}}}{\sum_{\mathrm{j}=1}^{\mathrm{m}} \sum_{\mathrm{i}=1}^{\mathrm{n}} \mathrm{E}_{\max , \mathrm{i}}}
$$

Onde:

ICS = Índice de capital social;

$\mathrm{E}_{\mathrm{ij}}=$ escore da i-ésima variável obtida pela j-ésima comunidade;

$\mathrm{E}_{\max , \mathrm{i}}=$ escore máximo da i-ésima variável;

$\mathrm{C}_{\mathrm{i}}=$ contribuição da variável "i” no índice de capital social;

$\mathrm{i}=1, \ldots \ldots \ldots . ., \mathrm{n}$, número de variáveis;

$\mathrm{j}=1, \ldots \ldots \ldots \ldots, \mathrm{m}$, número de comunidades.

O valor do Índice de Capital Social (ISC) varia de 0 a 1. Assim, quanto mais próximo de 1 , maior o nível de acumulação do capital social nas comunidades. Para verificar o nível de acumulação do capital social, optou-se por estabelecer o seguinte critério:

a) Baixo nível de acumulação de capital social ............ $0<$ ISC $\leq 0,5$

b) Médio nível de acumulação de capital social ......... 0,5 < ISC $\leq 0,8$

c) Alto nível de acumulação de capital social ............ 0,8 < ISC $\leq 1,0$

Na identificação do capital tangível foi realizada uma análise tabular e descritiva do incremento de diversas variáveis entre o ano de 1998 (ano 
base - período das implantações dos projetos) e o ano de 2001 (época desta pesquisa) tais como: número de escolas, número de postos de saúde, número de ligações de energia elétrica, fontes de abastecimento de água, saneamento, entre outros.

\section{Amostra}

A seleção dos subprojetos se deu em virtude da maior concentração do número de famílias beneficiadas. Desta forma, foram selecionados quatro tipos de subprojetos: abastecimento de água, ação fundiária, eletrificação rural e mecanização agrícola. A estratificação das unidades a serem pesquisadas por cada tipo de subprojeto teve por base a classificação destas como boa, regular e ruim, conforme técnicos de extensão rural e profissionais ( corpo técnico) responsáveis pelo projeto São José.

Por sua vez, na seleção das comunidades, foram utilizados os seguintes critérios: o tipo do subprojeto e a distribuição geográfica das comunidades. A amostra ficou distribuída da seguinte maneira: sete comunidades contendo subprojetos de abastecimento de água, oito de eletrificação rural, seis de mecanização agrícola e seis de ação fundiária ficando a amostra composta de 27 comunidades nas quais foram entrevistados 27 líderes ou seus representantes e 54 beneficiários do programa.

\section{Resultados e discussão}

\section{Capital Social Intangível}

Para possibilitar maior conhecimento da situação atual do capital social intangível e sua composição nas comunidades selecionadas, fezse a análise das variáveis que o compõem.

Inicialmente indagou-se sobre as tomadas de decisão relativas aos problemas da Associação. A maior parte dos beneficiários afirmou que estas sempre são tomadas pelos sócios através de reuniões convocadas pelos dirigentes da Associação.

Considerando as associações como um todo, aproximadamente, 41,00\% das comunidades pesquisadas apresentaram elevação no número de seus sócios, enquanto que 33,33\% indicaram declínio. 
O número de sócios no subprojeto ação fundiária declinou ou permaneceu estável nos últimos anos. Segundo líderes entrevistados, o declínio é resultado da desistência de sócios que ocorreu em alguns subprojetos de ação fundiária, por considerarem que, no momento acordado, não teriam condições de cumprir com os compromissos assumidos junto às instituições financeiras, o que, em parte, é reflexo da escassez das chuvas em alguns anos em determinadas regiões e, em parte, em razão da necessidade de mais acompanhamento e assistência técnica. Também foi mencionado, na justificativa das dificuldades encontradas, a supervalorização da terra na época da compra, que fez com que suas dívidas alcançassem um patamar muito elevado.

No caso dos subprojetos de eletrificação rural, houve aumento do número de sócios em cinco associações $(62,50 \%)$. Com relação aos subprojetos de abastecimento de água, houve declínio do número de sócios em uma associação e um aumento em quatro destas $(57,14 \%)$, que, por morarem próximos, procuraram beneficiar-se dos subprojetos. Em parte dos subprojetos de mecanização agrícola, alguns sócios migraram para outras localidades com expectativas de melhorias de vida.

No que diz respeito ao fornecimento da contrapartida dos financiamentos dos projetos pelas associações, vê-se que todas elas cumpriram integralmente suas obrigações relativas a este item. A contrapartida, em geral, foi cobrada à comunidade em forma de prestação de serviços (projetos de eletrificação rural e abastecimento de água) e na forma de construção de garagem ou abrigos para as máquinas (projeto de mecanização agrícola).

As informações obtidas indicam que $57,14 \%$ das comunidades beneficiadas pelos subprojetos de abastecimento de água não têm nenhuma responsabilidade sobre a operação e manutenção dos referidos subprojetos. Isto se justifica pela participação das prefeituras dos municípios nos quais referidas comunidades estão inseridas, que, nestes casos, ampliam com recursos próprios os projetos originais, com a finalidade de beneficiar outras comunidades vizinhas, ficando, assim, o controle da operação destes para o município ou estado. Os subprojetos de eletrificação estão sob a responsabilidade de uma empresa de energia do Estado do Ceará. As associações das comunidades beneficiadas pelos subprojetos de ação fundiária e mecanização agrícola têm o controle e a responsabilidade sobre a operação e manutenção destes. 
Procurou-se saber sobre a existência de pagamento de cotas (taxas) mensais por parte dos seus membros às Associações. As informações indicam que, na maioria, esta taxa é cobrada por seus dirigentes $(70,37 \%)$ e que 55,56\% dos participantes estão em dia com estes compromissos.

Os resultados mostram que 59,26\% das associações estudadas não têm fontes próprias de recursos. Aquelas beneficiadas pelos subprojetos de mecanização $(83,33 \%)$ e ação fundiária que também obtiveram financiamentos através do Projeto São José, para compra de tratores (50,00 \%), alugam estas máquinas para associados (por um preço mais baixo) e para não associados ou para prefeituras locais, obtendo, assim, recursos suficientes para atender suas necessidades financeiras.

Com relação às informações sobre a regularidade das reuniões, observou-se que, das 27 associações em estudo, 21 convocam seus membros através dos dirigentes, e realizam, pelo menos, uma reunião em cada três meses. Entretanto, estas reuniões não são planejadas e realizadas com a mesma freqüência pelos dirigentes nas associações beneficiadas pelos projetos de eletrificação rural e abastecimento de água, com um percentual de 50,00 e 28,57, respectivamente .

Indagou-se sobre a participação (ou não) das associações nas negociações de empréstimos para seus membros junto às instituições financeiras e comerciais. Verificou-se que $83,33 \%$ das associações beneficiadas pelos subprojetos de ação fundiária conseguiram financiamentos através de projetos produtivos financiados pelo PRONAF. Deve-se esclarecer que estes projetos estão, em geral, relacionados à compra de animais (particularmente ovinos e caprinos) que, a princípio, possibilita condições de pagamento das dívidas dos assentados junto às instituições financeiras.

Verificou-se que as associações de outros subprojetos não tentaram ou não conseguiram negociar nenhum projeto junto às instituições financeiras ou comerciais. Este fato reflete a burocracia, falta de aval e a condição de não proprietário de parte dos beneficiários.

De acordo com dirigentes das associações, aproximadamente, a metade deles representa suas comunidades em conselhos municipais ou em reuniões convocadas pelo Executivo Municipal ou outros órgãos, para discutir assuntos específicos de interesse do município.

Procurou-se conhecer a capacidade das associações de mobilizar seus sócios para buscar soluções relativas aos problemas das comunidades. 
Capital Social das Comunidades Beneficiadas pelo Programa de Combate à Pobreza Rural PCPR/Projeto São José - PSJ - Estado do Ceará

Nota-se que um terço destas não é capaz de realizar referida mobilização. Deve-se mencionar que algumas associações foram apontadas pelos sócios como as que não estão realizando reunião com freqüência.

Dentre as associações em estudo, 48,14\% renovaram menos de $25,00 \%$ do seu quadro de dirigentes na última eleição. Vários foram os motivos que levaram a esta situação: controle político de algumas famílias sobre a comunidade; reduzido número de sócios beneficiados por um determinado projeto (casos dos projetos de ação fundiária); desinteresse dos sócios em participar da administração; nível educacional dos sócios e a não-realização das reuniões em intervalos desejados, etc. Observouse, também, em alguma comunidade, que o presidente da Associação e alguns membros do Conselho Fiscal pertencem à mesma família.

Os resultados informam que somente $18,52 \%$ das associações em análise estão promovendo eventos sociais regularmente em forma de comemoração de safra, dia das mães, dia das crianças, etc., enquanto mais de $80,00 \%$ destas não comemoram nenhuma data especial. Esses tipos de eventos são importantes para promover os relacionamentos sociais entre as famílias dos sócios e melhorar o funcionamento das associações.

As associações permitem a inclusão de novos sócios e respeitam seus direitos de candidatar-se para qualquer cargo administrativo. Nenhuma destas demonstrou qualquer tipo de discriminação no sentido de proibir a adesão de sócios ou sua decisão de candidatar-se a qualquer que seja o cargo da diretoria da Associação.

Os dados apresentados na Tabela 1 mostram o índice de capital social intangível das comunidades beneficiadas pelos diferentes subprojetos e a contribuição absoluta de cada uma das variáveis que o compõe. Nos subprojetos de abastecimento de água e mecanização agrícola, cada variável pôde obter um valor máximo de 0,0714. Nos subprojetos de ação fundiária e eletrificação rural, o valor máximo que cada variável pode alcançar é de 0,0769, em razão de estes subprojetos apresentarem um número menor de variável relativamente aos outros já mencionados.

Verifica-se que, dentre as variáveis que apresentaram maior contribuição ao ICS, destacam-se: participação dos sócios na tomada de decisão, contrapartida da comunidade (onde se aplica), inclusão social e regularidade na realização das reuniões. Observa-se ainda que o ICS apresenta o menor valor nas comunidades beneficiadas pelos subproje- 
tos de abastecimento d'água e eletrificação rural e mostra maior valor nas comunidades que possuem os subprojetos de mecanização agrícola, seguido pelos de ação fundiária. Contudo, deve-se lembrar que o valor máximo atingível do ICS é 1 (um). Como os valores calculados do ICS encontram-se no intervalo de 0,5 a 0,8 , constata-se que, de modo geral, as associações possuem médio nível de acumulação de capital social para todos os tipos de subprojetos.

Tabela 1 - Participação das variáveis na composição do Índice de Capital Social Intangível das comunidades beneficiadas pelo Programa de Combate à Pobreza Rural no ano de 2001, Ceará.

\begin{tabular}{l|c|c|c|c}
\hline \multicolumn{1}{c|}{ Variável } & $\begin{array}{c}\text { Abasteci- } \\
\text { mento } \\
\text { D’água }\end{array}$ & $\begin{array}{c}\text { Ação } \\
\text { Fundiária }\end{array}$ & $\begin{array}{c}\text { Eletrifi- } \\
\text { cação } \\
\text { Rural }\end{array}$ & $\begin{array}{c}\text { Mecani- } \\
\text { zação } \\
\text { Agrícola }\end{array}$ \\
\hline - Pabprojeto & & & & \\
- decisões & 0,0714 & 0,0769 & 0,0769 & 0,0714 \\
- Variação dos no número de sócios & 0,0510 & 0,0192 & 0,0529 & 0,0298 \\
- Contrapartida da comunidade & 0,0714 & NSA & 0,0769 & 0,0714 \\
- Operação e manutenção do subprojeto & 0,0306 & 0,0769 & NSA & 0,0714 \\
- Cota taxa) mensal & 0,0408 & 0,0577 & 0,0385 & 0,0536 \\
- Fonte própria de recursos & 0,0204 & 0,0385 & 0,0048 & 0,0595 \\
- Fonte externa de recursos & 0,0000 & 0,0000 & 0,0048 & 0,0000 \\
- Regularidade das reuniões & 0,0612 & 0,0769 & 0,0577 & 0,0714 \\
- Participação da Associação no & & & & \\
- agenciamento de empréstimos & 0,0000 & 0,0641 & 0,0000 & 0,0000 \\
- Representação em conselhos municipais & 0,0408 & 0,0385 & 0,0385 & 0,0357 \\
- Renacidade de mobilização & 0,0561 & 0,0577 & 0,0625 & 0,0476 \\
- Promoçãa do corpo de dirigentes & 0,0204 & 0,0256 & 0,0433 & 0,0238 \\
- Inclusão de eventos sociais & 0,0102 & 0,0128 & 0,0096 & 0,0357 \\
Indice de capital social & 0,0714 & 0,0769 & 0,0769 & 0,0714 \\
\hline
\end{tabular}

Fonte: Dados da pesquisa

NSA (não se aplica).

\section{Capital Social Tangível}

Os resultados expressos na Tabela 2 indicam que houve pequena ampliação dos serviços educacionais de ensino fundamental, especialmente da $1^{\mathrm{a}}$ a $4^{\mathrm{a}}$ série. Os dados mostram que não houve nenhuma alteração no número de escolas públicas do ensino fundamental ( $5^{\mathrm{a}}$ a $8^{\mathrm{a}}$ série) e ensino médio. A facilidade de transportes oferecidos pelas prefeituras está viabilizando o acesso da população que faz o ensino fundamental ( $5^{\mathrm{a}}$ a $8^{\mathrm{a}}$ série) e ensino médio para estudar em outras comunidades ou sedes 
dos municípios. Contudo, as facilidades de alfabetização de adultos e o número de creches aumentaram ao longo do período em estudo. Deve-se esclarecer que as creches e os cursos de alfabetização de adultos funcionam nas benfeitorias nas quais são ministrados os cursos do ensino fundamental ( $1^{\text {a }}$ a $4^{\text {a }}$ série).

A educação é uma variável para a qual se percebe mudanças no longo prazo. Construções de escolas públicas no setor rural que proporcionem conhecimentos em todos os níveis constituem-se acumulação de capital humano nas famílias pobres, que não só as beneficia dando condições de competir em outros setores produtivos, como também favorece a sociedade como um todo, uma vez que o maior nível de escolaridade contribui para reduzir os problemas relacionados a saneamento básico e a doenças.

Tabela 2 - Incremento da quantidade de escolas públicas no período entre 1998 a 2001, nas diversas comunidades selecionadas, segundo o tipo de subprojeto no Estado do Ceará.

\begin{tabular}{l|c|ccc}
\hline \multirow{2}{*}{ Subprojeto } & \multirow{2}{*}{ No de Comunidade } & \multicolumn{3}{|c}{ Escola Pública } \\
\cline { 3 - 5 } & & Ens.Fundam. & Pré-Alfabetização & Creche \\
\hline Abastecimento d'água & 7 & 1 & 0 & 3 \\
Ação fundiária & 6 & 2 & 0 & 2 \\
Eletrificação rural & 8 & 2 & 2 & 1 \\
Mecanização agrícola & 7 & 1 & 1 & 1 \\
\hline Amostra Total & 28 & 6 & 3 & 7 \\
\hline
\end{tabular}

Fonte: Dados da pesquisa

Silva e Khan (1996), ao analisarem a importância do nível educacional do agricultor na geração da renda rural, concluíram que este fator tem influência positiva no valor da produção, proporcionando aumento expressivo na eficiência técnica e econômica.

Investimentos em saúde representam uma contribuição de longo prazo para a redução da pobreza no setor rural. Os resultados apresentados na Tabela 3 mostram que o PCPR/PSJ possibilitou melhorias em relação às condições de serviços de saúde oferecidos anteriormente, tendo em vista o aumento do número de postos de saúde nos últimos anos (intervalo deste estudo). Todas as famílias nas comunidades estudadas têm acesso, uma vez por mês, a serviços de saúde (através da visita de agente 
de saúde). Em algumas comunidades, equipes médicas (enfermeiras e às vezes dentistas) fazem uma visita através do Programa Médico da Família, cuja prioridade é dada às crianças e gestantes.

Segundo Cohn e Elias, citados por Monte (1999), "a oferta de serviços de saúde é um direito mínimo universal do cidadão e é fundamental que ele seja universalizado, principalmente numa sociedade tão extremamente diferente como a cearense".

Com relação ao número de ligações de energia elétrica, os dados contidos na referida tabela mostram que houve um incremento de mais de mil famílias com acesso a este serviço. Observa-se que algumas famílias beneficiárias do subprojeto ação fundiária, mecanização agrícola e abastecimento d'água também usufruíram do subprojeto de eletrificação rural. Um aumento no número das ligações comerciais foi também verificado em comunidades beneficiadas não só pelos subprojetos de eletrificação rural como também pelo subprojeto de abastecimento d'água.

As informações relativas ao acesso a serviços telefônicos nas comunidades selecionadas indicam um substancial incremento no número de usuários deste serviço.

Os resultados sobre os serviços de abastecimento d'água revelam que o número de ligações domiciliares, chafarizes e outros (poços, cacimbas, cacimbões, etc.) aumentou ao longo do período em estudo. A água de boa qualidade é uma condição necessária para a população rural viver com saúde e bem-estar. As informações indicam que o acesso à água aumentou para o consumo humano (beber, tomar banho, etc.), para o consumo animal e para algumas famílias cultivarem frutas nos seus quintais.

No que diz respeito ao saneamento, observou-se que o número de fossas sépticas aumentou em todas as comunidades. O acréscimo mais significativo foi encontrado nas comunidades que possuíam subprojeto de abastecimento d'água; e em segundo lugar, nas comunidades com subprojetos de ação fundiária que também são beneficiárias de subprojetos de moradia, o que possibilitou a construção das referidas fossas. 
114 - Capital Social das Comunidades Beneficiadas pelo Programa de Combate à Pobreza Rural PCPR/Projeto São José - PSJ - Estado do Ceará

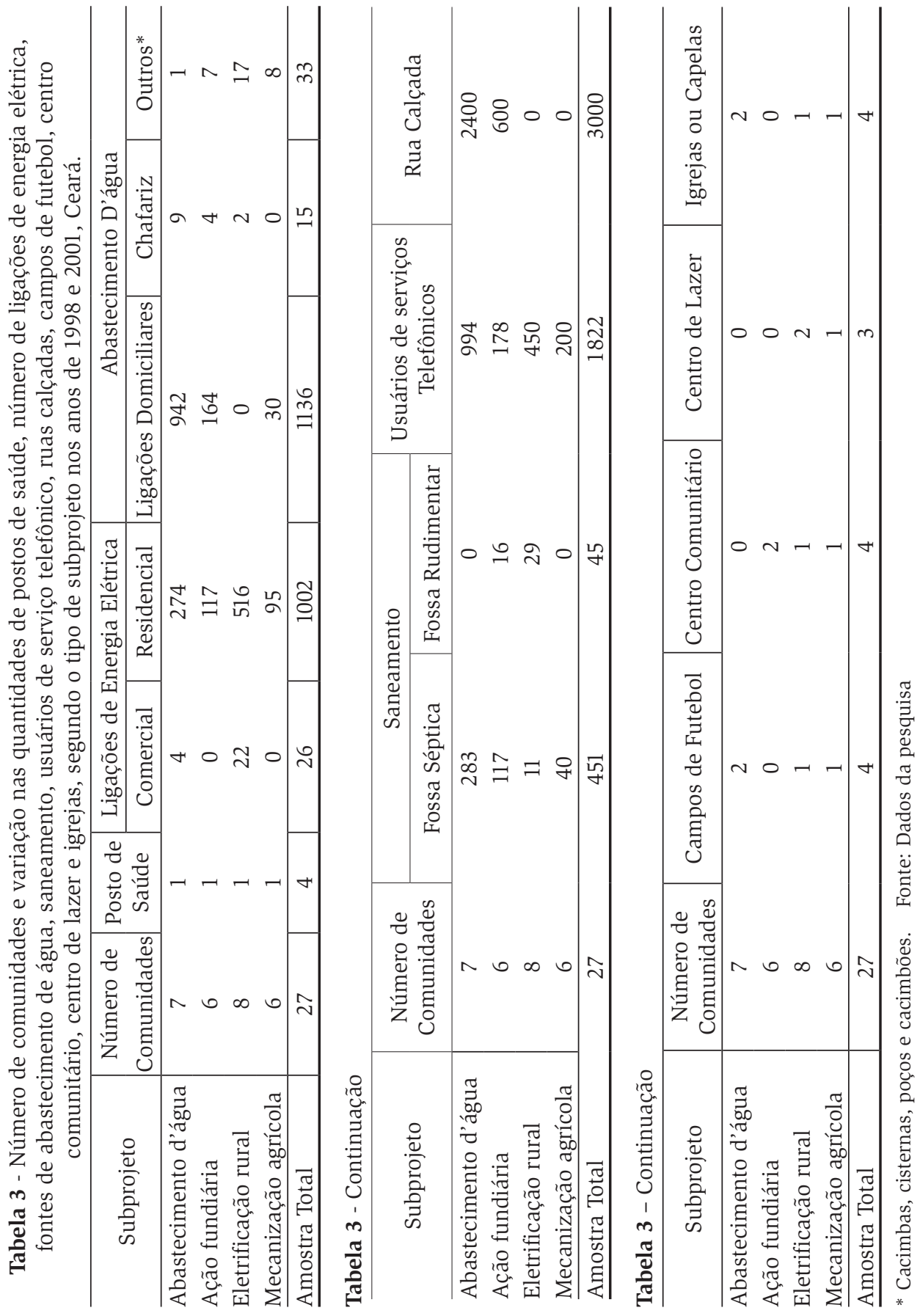


Verificou-se, ainda, incremento no número de praças de esporte (campos de futebol), centros comunitários, centros de lazer, igrejas ou capelas após a implantação dos referidos subprojetos. Desta forma, pode-se afirmar que as opções de lazer, encontros sociais e religiosos aumentaram ao longo do período analisado.

Constata-se que todos os indicadores de capital social tangível das comunidades consideradas nesta pesquisa melhoraram, em maior ou menor escala, depois da implantação do PCPR/PSJ.

Os resultados apresentados no estudo corroboram com a concepção do Projeto São José que considera que a redução da pobreza e o fortalecimento da cidadania no mundo rural dependem, fundamentalmente, da criação de alguma forma de capital social que seja capaz de utilizar tanto recursos locais como recursos externos para enfrentar a pobreza, superar problemas da comunidade que não poderiam ser observados individualmente, criar oportunidades de gerar rendas e aproveitar potencialidades locais. Neste sentido, as ações do programa deveriam contribuir para criar capital social e para demonstrar um processo de mobilização das comunidades em favor do próprio desenvolvimento.

\section{Conclusões e sugestões}

Apesar da redução do número de sócios em algumas associações, houve ampliação deste número na maioria destas. Em geral somente os subprojetos de mecanização possuem fonte própria de recursos gerados pelo aluguel das máquinas. Por ouro lado, parte das associações não cobra taxas de seus sócios e quando o fazem, o valor é irrisório.

As associações beneficiárias dos subprojetos de eletrificação rural são as que menos estão organizadas e têm pouca participação dos seus sócios em reuniões.

Somente as associações com subprojetos de ação fundiária conseguiram novos financiamentos para as comunidades, em geral, para projetos produtivos.

Considerando a amostra como um todo, não se verificaram mudanças em grande parte dos dirigentes das Associações.

O valor do Índice de Capital Social (ICS) demonstrou que as associações possuem um médio nível de acumulação de capital social das comunidades 
em todos os tipos de subprojetos. Os subprojetos que apresentaram maiores índices de capital social intangível foram os de ação social e mecanização. No que se refere ao capital social tangível houve incremento em todas as variáveis analisadas conseqüentemente neste tipo de capital.

Pode-se concluir, que os recursos aplicados pelo PCPR/PSJ contribuíram para avanços significativos no capital social intangível e tangível das associações e/ou comunidades.

Sugere-se que haja intensificação do acompanhamento dos subprojetos financiados com recursos do PCPR/PSJ para garantir a operação e manutenção adequada e, conseqüentemente, garantir maior sucesso dos investimentos feitos.

Considera-se importante propiciar alguns cursos relativos a associativismo para todos os beneficiários e sobre organização, especialmente, para os dirigentes ou líderes comunitários através de organizações cooperativistas do Estado com experiência nessa área.

Em razão da crescente demanda por serviços de assistência técnica e extensão rural, sugere-se que o Governo do Estado do Ceará amplie o quadro de técnicos através de novos concursos para a orientação e difusão de tecnologias destinadas especialmente ao pequeno produtor.

Sugere-se, por fim, um estudo detalhado sobre geração de emprego e renda advindos dos investimentos feitos nos subprojetos do PCPR/PSJ.

\section{Referências bibliográficas}

CEARÁ. Secretaria de Desenvolvimento Rural. Projeto São José - Relatório de Avaliação- 1998. Fortaleza, 1998. 74p.

FOX, J. How does civil societ thicken?: The political construction of social capital in rural Mexico.[s.l.], World Development. V.24, n. 9, p. 1089-1103. set, 1996.

FUKUYAMA, F. Social capital and the global economy. [s.l.], Foreign Affairs. V.74, n.5, p. 89-99. mar, 1995.

FUKUYAMA, F. Social capital and civil society. Prepared for the International Monetery Fund Conference on Second Generation Reforms, 1999. Disponível em: < http: www.imf.org/external/pubs/ft/seminar/1999/reforms/fukuyama.html.1999 > Acesso em Mar.2002. 
GRANOVETTER, Mark S. Economic action and social structure: the problem of embedded ness. [s.l.], American Journal of sociology. V.91, n.3, p. 481-510, set, 1985.

JARA, C. J. Capital social e desenvolvimento local sustentável. Equador: Instituto Interamericano de Cooperação para Agricultura, 1999. 29p.

KLIKSBERG, Bernardo. El rol del capital social y de la cultura en el proceso de desarrollo. In Capital social y cultura: claves estratégicas para el desarrollo. Banco Interamericano de Desarrollo. Washington 2000.

KNACK, Snack, S. e P. Keefer. Does social capital have an economic payoff ? Across Country investigation. Quarterly Journal of Economics. Local. v.112, n.4. p. 1251-1288. nov.1997.

LAZARINI, S.; CHADDAD F. R.; NEVES, M. F. O conceito de capital social e aplicações para o desenvolvimento e estratégia sustentável. Disponível em: < http:/www.capitalsocial.cbj.net > . Acesso: 10 abr.2003

MONASTÉRIO. L.M. Capital social e economia: antecedentes e perspectivas. Disponível em: $<$ http//www.capitalsocial.cbj.net $>$. Acesso: 10 abr. 2003

MONTE, F.S.S. Efeito da implantação do complexo industrial e portuário do Pecém-CE na qualidade de vida das famílias rurais da Região: o caso do reassentamento Cambeba. 1999. 144f. Dissertação (Mestrado em Economia Rural), Departamento de Economia Agrícola, Centro de Ciências Agrárias, Universidade Federal do Ceará, Fortaleza, 1999.

PUTNAM, R.D. Comunidade e democracia: a experiência da Itália moderna. 2. ed. Rio de Janeiro: FGV, 2000.

SILVA, L.M.R. e KHAN, A S. Educação, produção e eficiência na utilização dos fatores de Produção na Região semi-árida do Nordeste. In: CONGRESSO BRASILEIRO DE ECONOMIA E SOCIOLOGIA RURAL, Aracaju-Se. Anais... Brasília: SOBER, 1996.

WORLD BANK. Conceitos disponíveis no site do Banco Mundial. Disponível em < http:www.worldbank.org/poverty/s.capital > Acesso em: 23 mar.2000. 